\title{
BILATERAL VARIATIONS IN THE BRANCHING PATTERN OF THE LATERAL CORD OF BRACHIAL PLEXUS: A CASE REPORT
}

\author{
Nagaraj. S ${ }^{* 1}$, Rohini Arathala ${ }^{2}$, Vishwajit Deshmukh ${ }^{3}$, Payal Kasat ${ }^{4}$ \\ ${ }^{* 1}$ Assistant Professor, Department of Anatomy, JIPMER Karaikal, India. \\ ${ }^{2}$ Tutor, Department of Anatomy, JIPMER Karaikal, India. \\ ${ }^{3}$ Assistant Professor, Department of Anatomy, AlIMS Nagpur, India. \\ ${ }^{4}$ Senior resident, Department of Anatomy, AlIMS Nagpur, India.
}

\section{ABSTRACT}

Variations in the branches of the brachial plexus are not uncommon. In the present report, variation in the branching pattern of the lateral cord is described along with the absence of the musculocutaneous nerve. The lateral cutaneous nerve of the forearm was a direct continuation of the lateral cord. These kinds of variations of nerve branches are more prone to injuries during upper arm and axillary surgeries. Knowledge regarding variations in the brachial plexus is utmost important for surgeons, anesthesiologist, clinicians and anatomists. KEYWORDS: Musculocutaneous nerve, Lateral cord, Median nerve, Variation.

Address for Correspondence: Dr. Ngaraj. S, Assistant Professor, Department of Anatomy, JIPMER, APJ Abdul Kalam Block, Thirunallar bypass road, Karaikal -609602, India.

E-Mail: cdrnagraj@gmail.com

Access this Article online

Quick Response code

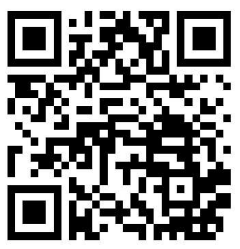

DOI: $10.16965 /$ ijar.2019.196

\begin{tabular}{|c|c|c|}
\hline \multicolumn{3}{|c|}{ Journal Information } \\
\hline \multicolumn{3}{|c|}{ 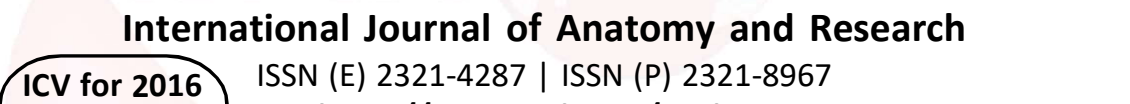 } \\
\hline \multicolumn{3}{|c|}{ Article Information } \\
\hline $\begin{array}{l}\text { Received: } 05 \text { Apr } 2019 \\
\text { Peer Review: } 07 \text { Apr } 2019 \\
\text { Revised: None }\end{array}$ & $\begin{array}{l}\text { Accepted: } 06 \text { Ma } \\
\text { Published (O): } 05 \\
\text { Published (P): } 05\end{array}$ & $\begin{array}{l}19 \\
2019 \\
2019\end{array}$ \\
\hline
\end{tabular}

\section{INTRODUCTION}

Profound understanding of human neural system anatomy is the key to success in elective neurosurgeries. Also, while treating critical trauma patients, the quick surgical approach requires a sound knowledge of the possible variations of the nervous system. The extremities, particularly upper limb, are more susceptible to trauma. A variation in the branching pattern of brachial plexus is one of the important challenges in such a situation.

The branches arising from brachial plexus are cutaneous and muscular. So, any injury at this level may lead to severe disability in day-to-day functions. Normally the ventral rami of roots of C5-C8 and T1 nerves form the brachial plexus.
These rami unite to form the trunks, divisions, cords and branches of brachial plexus. The brachial plexus branches extend from the inferolateral portion of the neck to the posterior surface of the clavicle and enter the axilla, grouped around the axillary artery [1]. According to the literature, lateral and medial roots form lateral and medial cords form the median nerve. Usually, medial root crosses the third part of the axillary artery to unite with the lateral cord and forms the median nerve, either anterior or lateral to the artery [2].

The musculocutaneous nerve $(C 5,6,7)$ is a branch of lateral cord, normally pierces the coracobrachialis muscle and runs between the biceps brachii and brachialis muscles. At the 
Nagaraj.S, et al., BILATERALVARIATIONS IN THE BRANCHING PATTERN OF THE LATERAL CORD OF BRACHIAL PLEXUS: A CASE REPORT.

elbow, it runs in lateral relation to the biceps tendon to continue further as a lateral cutaneous nerve of forearm [2].

The presence of anatomic variations in the peripheral nervous system may be responsible for unusual clinical findings in the patients and might explain symptoms and varied presentations such as vascular compression. This case describes an interesting and rare variation in the position and formation of the median nerve, an atypical formation of the median nerve by three roots in the right upper limb, absence of the musculocutaneous nerve and continuation of the lateral cord as lateral cutaneous nerve of the forearm in both the limbs.

\section{CASE REPORT}

During routine upper limb dissection for first-year medical students, the brachial plexus of a 60 years old male cadaver showed a variation in the branching pattern of the brachial plexus. The cadaver was donated to medical college and the cause of death was unknown. The cadaver had no pathological and traumatic lesions or marks of any surgical procedures in the axilla and the upper limb. The dissection of the axilla, arm and cubital fossa had been performed carefully to trace the infraclavicular branches of the brachial plexus. The entire course of the median nerve and branches of the lateral cord were explored, the variations documented and necessary photographs were taken. The dissection revealed a variation in the formation of the median nerve, the absence of musculocutaneous nerve, the origin of direct muscular branches and the continuation of lateral cord as lateral cutaneous nerve of the forearm in both the upper limb. It was also observed that an additional anastomotic branch to the median nerve arose from the lateral cord in right upper limb.

On the right side, we observed five branches from the lateral cord. Three of these branches were noted as direct muscular branches from its lateral side, viz. first branch to the coracobrachialis, second branch to biceps brachii at about $7 \mathrm{cms}$ and the third branch to brachialis at about $8.5 \mathrm{cms}$ from coracobrachialis. Apart from these, there were two anastomotic branches from the lateral cord at different levels and were labeled as upper and lower anastomotic branches. The upper branch (LR 1) was long and thin $(4.1 \mathrm{~cm})$, crossed the third part of the axillary artery from lateral to the medial side, and joined with medial root $(5 \mathrm{~cm})$ of medial cord. The median nerve thus formed (Fig.1) was medial to the axillary artery, which occurs rarely. The lateral cord at about $8.5 . \mathrm{cm}$ below the upper anastomotic branch to median nerve gave off medial and lateral branches.

Fig. 1: Photograph showing the branching pattern of the lateral cord in the right arm. LC: Lateral Cord, AA: Axillary artery, MC: Medical Cord, MR: Medial Root of median nerve, LR: Lateral root of Median nerve, LCNF: Lateral cutaneous nerve of forearm, MN: Median nerve, MCNF: Medial cutaneous nerve of forearm.

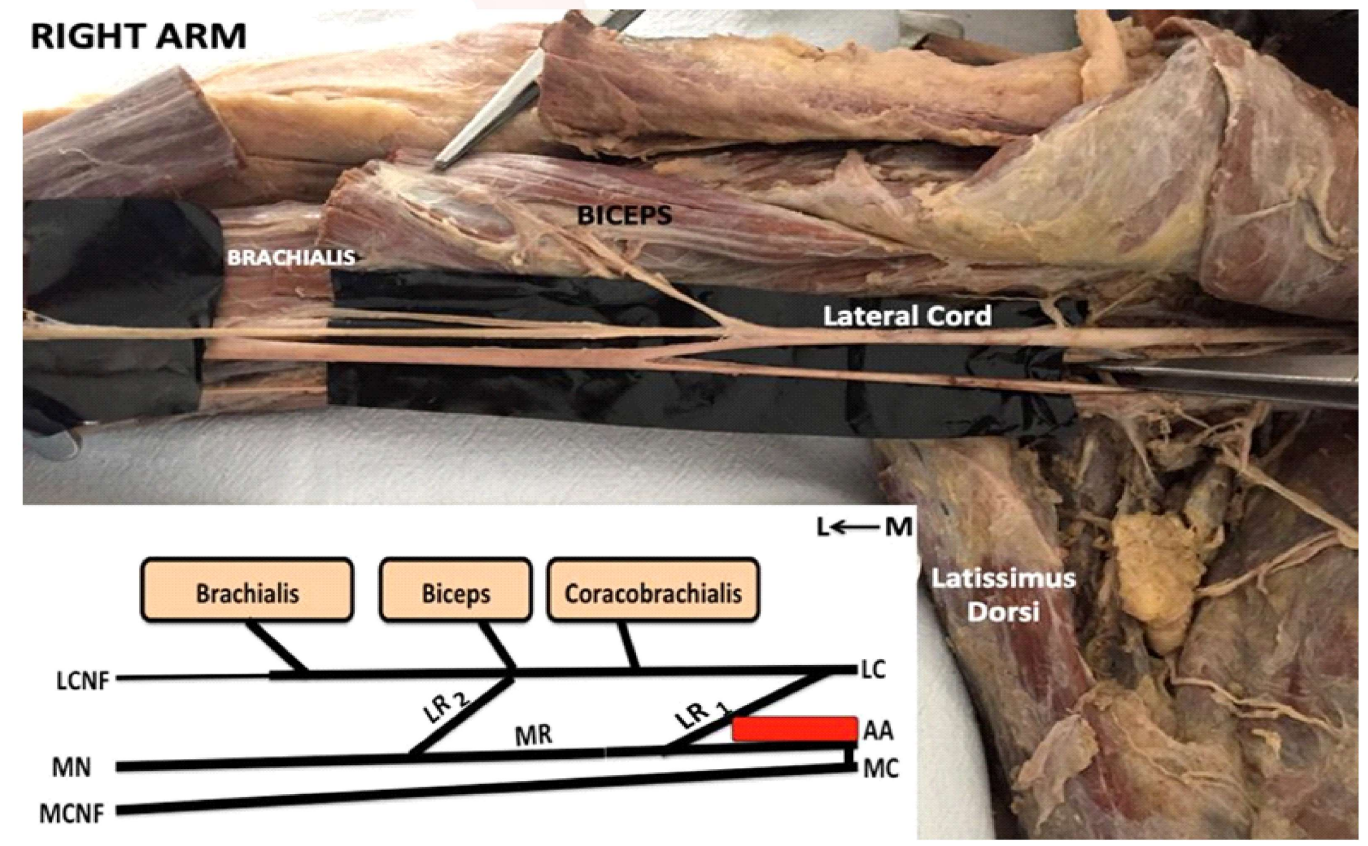


Fig. 2:Photograph showing the branching pattern of the lateral cord in the left arm. CB: Coracobrachialis, LD: Lattisimus Dorsi muscle, LC: Lateral Cord, AA: Axillary artery, MC: Medical Cord, MR: Medial Root of median nerve, LR: Lateral root of Median nerve, LCNF: Lateral cutaneous nerve of forearm, MN: Median nerve, MCNF: Medial cutaneous nerve of forearm.

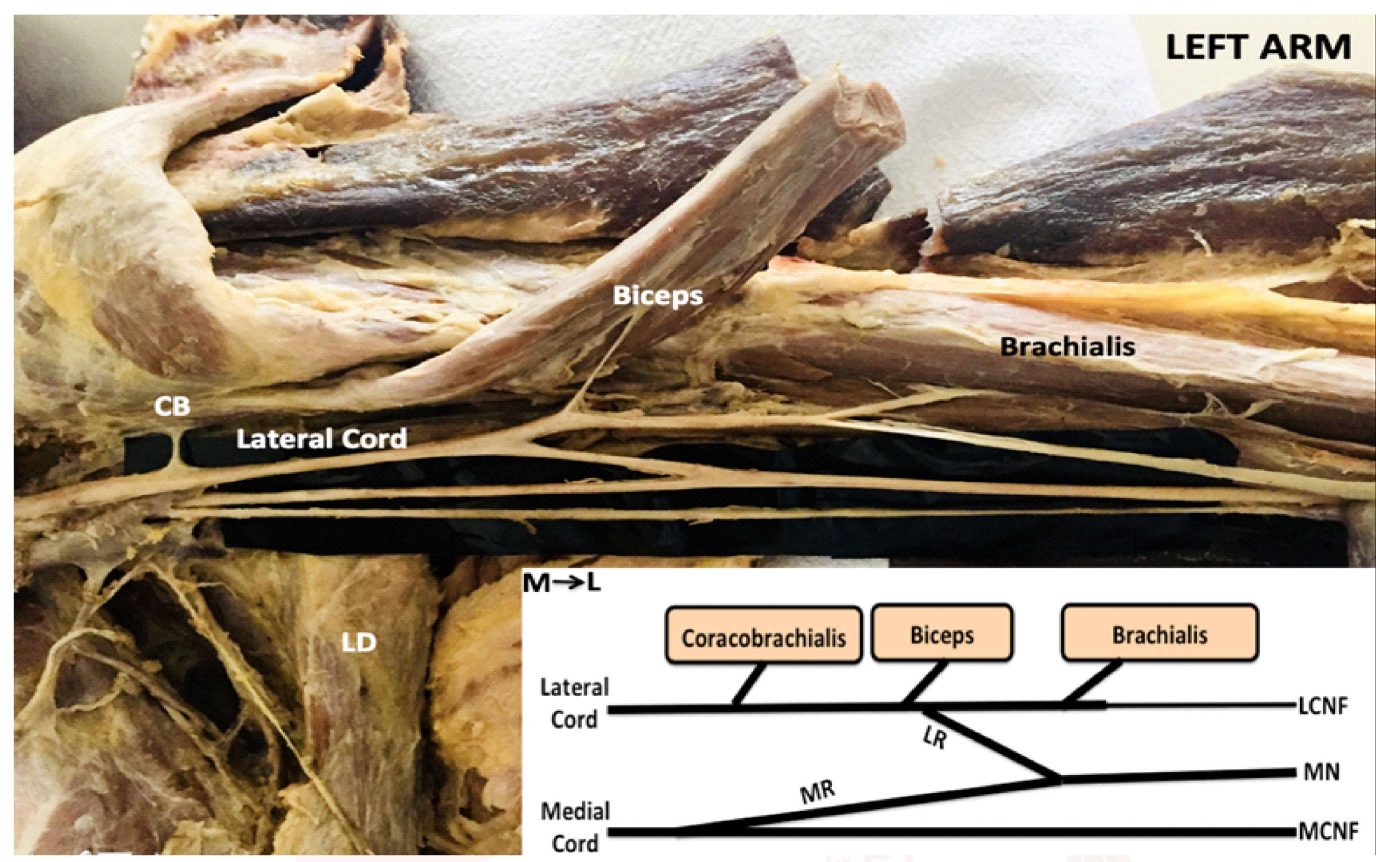

The lateral branch ended in the biceps brachii and medial branch, which was noted as a lower anastomotic branch (LR 2) was shorter and thicker $(2.2 \mathrm{~cm})$ than an upper branch joined with median nerve in the proximal part of the arm. After giving these two branches lateral cord descended at about 2.2.cm in length then gave off a branch to brachialis at the medial border of the brachial artery and then lateral cord continued as a lateral cutaneous nerve of forearm. On the left side, we noticed the lateral cord gave muscular branches to the muscles of the anterior compartment of the arm directly, as musculo cutaneous nerve was absent. The branch to coracobrachialis supplied without piercing it(Fig 2).In addition, there was a variation in the median nerve formation. Median nerve was formed in the middle of the arm at about $9 \mathrm{cms}$ from branch to coracobrachialis by a short lateral root $(6.2 \mathrm{~cm})$ and a long medial root $(11 \mathrm{~cm})$, which arose from lateral and medial cords, respectively. The course and branching pattern of the lateral cord after its contribution to the median nerve formation was the same as that on the right side.

\section{DISCUSSION}

The aim of this paper is to report about the lateral cord, which is continued as a lateral cutaneous nerve of the forearm, which we found during dissection on the right limb. It will also furnish details about the absence of musculocutaneous nerve, direct branches to the muscles of the anterior compartment of the arm from the lateral cord and additional communications between the lateral cord and median nerve in the arm.

The present report noted multiple variations of lateral cord on both the sides. i.e. direct branches from lateral cord supplied the anterior compartment muscles of the arm and lateral cord gave additional branch to the median nerve in the mid-arm and further down continued as the lateral cutaneous nerve of forearm. As per our knowledge, this kind of variation has not been reported earlier. This case also characterized by the absence of the musculocutaneous nerve on both sides. Jamuna observed the absence of musculocutaneous nerve in 3 limbs out of 50 limbs [3].

Akin to our finding of nerve branch supplying to coracobrachialis without piercing it on left side, Jagadishbabu also noted similarly in two limbs [4].The incidence of variation in the brachial plexus was more common in the females and on the right side, which was noted in the previous study conducted on fetuses [5].

Although the cause of these anomalies in nerve formation is not fully understood, two popular 
theories have been put forward to provide possible explanations are - chemotropism hypothesis [9] and principle of contact guidance [7]. According to the theory of chemotropism, during the embryological development, axonal growth is guided by the chemical attraction emanating from the target area to be innervated located far away [8]. Improper chemical signals by the mesenchymal cells in the limb bud can change pattern of formation of peripheral nerve plexus. The altered structures once formed would persist postnatally [9].

The contact guidance mechanism, on the other hand highlights the importance of cell-cell and cell-matrix interactions in the immediate vicinity of the axonal growth cone involving transcription factors like neural cell adhesion molecule (N-CAM) and $L 1$, cadherins and integrins which help in the process of axonal path finding [8].A complete understanding of the cause of variations in the brachial plexus demands further probe of such molecules and their role.

On the left side, the median nerve was formed by two roots at the middle one-third of the arm. But in the case ofright arm, two roots coming from the lateral cord and one root from the medial cord formed the median nerve. There are certain studies reporting the formation of the median nerve by the additional branches arising from the lateral cord [10]. The knowledge of such rare median nerve variations is also important for anaesthetists to administer nerve blocks in the arm [11].

Usually, both the roots of the median nerve join lateral to the axillary artery to form the median nerve. In the present case upper and lower communicating roots of lateral cord crossed the axillary and brachial artery at an oblique angle to join the median nerve. Thus, the median nerve formed was medial to the artery. Because of the crossing of the lateral root of the median nerve may compress the arteries, which could cause ischemia. Hence, anticipation and prior recognition of such variations is important for the surgeons while performing surgeries in this region. The significance of variations noted in the current case has possible clinical implications and hence utilitarian for the anatomists, anaesthetists and radiologists alike.

\section{CONCLUSION}

These observations show that variations in the lateral cord and median nerve formation have important clinical impact. It is important to remember such anatomical variations during clinical approaches where these additional branches are prone to get damaged.

\section{Conflicts of Interests: None}

\section{REFERENCES}

[1]. Hollinshead WH. Anatomy for surgeons. In: The back andlimbs. 1st ed. New York:Harper and Row, 1966, pp 220-240.

[2]. Standring S. Gray's Anatomy $40^{\text {th }}$ edition. Churchill Livingstone. El-sevier, New York, 2005, pp 821-822

[3]. Jamuna M, Amudha G. A cadaveric study on the anatomic variations of the musculocutaneous nerve in the infraclavicular part of the branchial plexus. J Clin Diagn Res.2011;5(6):1144-47.

[4]. Babu DJ, Pillai TJ, Priyanka KD, Jalaja Y, Kumar US. A study on variations of musculocutaneous nerve in adult cadavers. IOSR J Dental and Med Sci. 2016;15(5):14-7.

[5]. Uysal II, a eker M, Karabulut AK, Büyükmumcu M, Ziylan T. Brachial plexus variations in human fetuses. Neurosurgery. 2003 Sep 1;53(3):676-84.

[6]. Ramon y, Cajal S. Accion neurotropica de los epitelios. Algunos detalles sobreel mecanismo genetico de las ramificaciones nerviosas intraepiteliales sensitivasy sensoriales. Trab Lab Invest Biol 1919; 17: 65-8.

[7]. Weiss P. Nerve patterns: the mechanics of nerve growth.Growth (suppl 5) 1941; 163-203.

[8]. Williams PL, Bannister LH, Berry MM et al. Gray's Anatomy. In:Nervous System.38th ed.London Churchill Livingstone, 1999: 1270.

[9]. Sannes HD, Reh TA, Harris WA. Development of the nervous system In: Axon growth and guidance. New York: Academic Press, 2000, pp. 189-197.

[10]. Das $S$ and PaulS. Anomalous branching pattern of lateral cord of brachial plexus. Int. J.Morphol. 2005;23(4):289-92.

[11]. Pianezza A, Salces y Nedeo A, Chaynes P, Bickler PE, Minville $V$. The emergence level of the musculocutaneous nerve from the brachial plexus: implications for infraclavicular nerve blocks. AnesthAnalg 2012;114(5):1131-3.

How to cite this article: Nagaraj. S, Rohini Arathala, Vishwajit Deshmukh, Payal Kasat. BILATERALVARIATIONS IN THE BRANCHING PATTERN OF THE LATERAL CORD OF BRACHIAL PLEXUS: A CASE REPORT. Int J Anat Res 2019;7(2.3):6648-6651. DOI: 10.16965/ijar.2019.196 